\title{
Bacterial glycocalyx integrity drives multicellular swarm biofilm dynamism
}

$7 \quad{ }^{1}$ Institut National de la Recherche Scientifique (INRS) — Centre Armand-Frappier Santé

8 Biotechnologie, Université du Québec, Institut Pasteur International Network, Laval, QC,

9 Canada

$10{ }^{2}$ PROTEO, the Quebec Network for Research on Protein Function, Engineering, and

11 Applications, Université Laval, Quebec, QC, Canada

$12{ }^{3}$ Department of Biology, Syracuse University, Syracuse, NY, USA

13

$14 \dagger$ equal contribution

$15 *$ corresponding author

16

17 Salim T. Islam

18 E-mail: salim.islam@inrs.ca

19 Phone: (+1) 450-687-5010 ext. 8897 


\section{ABSTRACT}

22 establishment and maintenance, leading to the formation of higher-order 3D structures conferring

23 numerous survival benefits to a cell community. In addition to a specific EPS glycocalyx, we

24 recently revealed that the social $\delta$-proteobacterium Myxococcus xanthus secretes a novel

25 biosurfactant polysaccharide (BPS), with both EPS and BPS polymers required for type IV pilus

26 (T4P)-dependent swarm expansion via spatio-specific biofilm expression profiles. Thus the

27 synergy between EPS and BPS secretion somehow modulates the multicellular lifecycle of $M$.

28 xanthus. Herein, we demonstrate that BPS secretion functionally-activates the EPS glycocalyx

29 via its destabilization, fundamentally altering the characteristics of the cell surface. This impacts

30 motility behaviours at the single-cell level as well as the aggregative capacity of cells in groups

31 via EPS fibril formation and T4P assembly. These changes modulate structuration of swarm

32 biofilms via cell layering, likely contributing to the formation of internal swarm polysaccharide

33 architecture. Together, these data reveal the manner by which the interplay between two

34 secreted polymers induces single-cell changes that modulate swarm biofilm communities. 


\section{INTRODUCTION}

The detection of glycocalyces surrounding bacterial cells remains a seminal discovery in

37 bacterial physiology, giving rise to the biofilm concept for surface-attached microbial

38 community growth within a polysaccharide matrix (1). Within a biofilm, bacteria can physically interact, be protected from external stressors (e.g. antibiotics, reactive oxygen species, dehydration, etc.), replicate, communicate via secreted signals, and differentiate their functions $(2,3)$. While the importance of secreted polysaccharides for biofilm formation is widely

42 appreciated, the mechanisms by which these polymers promote 3D matrix structuration and the cellular organization within are areas of intense study (4). Myxococcus xanthus, a predatory Gram-negative $\delta$-proteobacterium $(2,5,6)$. Groups of $M$. xanthus cells are encased within a secreted polysaccharide matrix, promoting intimate contacts.

47 On surfaces, swarms of such cells are able to cooperatively predate prey microorganisms, saprophytically feeding on the degradation products. When nutrients become scarce, M. xanthus cells within a swarm biofilm secrete a signalling molecule that accumulates to a certain local threshold above which the developmental program is initiated, leading to the aggregation of

51 thousands of cells and the formation of fruiting bodies. Functional differentiation within the

52 swarm leads to three subpopulations, namely (i) myxospore-forming cells within the fruiting

53 body lumen, (ii) peripheral rods that remain at the base of the fruiting body, and (iii) motile

54 foragers that continue their outward trajectory from the initial aggregate (7).

Two motility systems are required to effectuate these complex physiological outcomes,

56 with each being differentially active depending on the nature of the substratum. On hard

57 surfaces, gliding (i.e. "adventurous" [A]) motility predominates, mediated by substratum 
coupling and directed transport of the trans-envelope Agl-Glt machinery at bacterial focal adhesion (bFA) sites (8-10). On soft substrata, cell groups move via type IV pilus (T4P)dependent (i.e. "social" $[\mathrm{S}])$ motility $(11,12)$. As a result of these complimentary systems, $M$.

61 xanthus forms highly structured, yet dynamic, biofilms. On hard substrata, M. xanthus swarm

62 biofilms expand along a radial vector as well as vertically away from the substratum, resulting in

63 the formation of stratified cell layers $(13,14)$. Cells within each layer are motile, densely

64 packed, and aligned along their long axes, displaying the properties of an active nematic liquidcrystal state of matter (15). This stratification on hard surfaces may require a functional gliding motility apparatus capable of coupling to an external contacting surface (e.g. the substratum and/or adjacent cells) as layer formation is severely compromised when the substratum-coupling adhesin of the Agl-Glt apparatus (CglB) is absent $(10,13)$. Prolonged incubation in such biofilms can lead to cells becoming connected via a network of outer-membrane vesicle (OMV) chains and OM tube (OMT) projections (16). In contrast, knowledge of internal swarm architecture on soft substrata is more limited. Of note, the leading edge of such swarms was shown via electron microscopy to contain discreet bundles of aligned cells, encased in

73 Ruthenium Red-stained structures termed polysaccharide "microchannels" (17). Several long-chain sugar polymers are synthesized by M. xanthus in order to modulate its complex lifecycle (18). For cells in development undergoing sporulation, the major spore coat (MASC) polymer is produced to surround myxospores in a protective layer $(19,20)$. For non-

77 sporulating cells, motility is affected by O-antigen-capped LPS (21-23), as well as a poorly 
81 secreted sugar polymer required for T4P-dependent swarm spreading, which inhibits natural

82

transformation and constitutes the principal matrix polysaccharide in M. xanthus biofilms (26-

31). Recently, we reported that M. xanthus also synthesizes and secretes a novel biosurfactant polysaccharide to the extracellular milieu that is essential for T4P-dependent swarm spreading (32). Within an expanding swarm biofilm, BPS biosynthetic machinery is more highly expressed in the swarm centre, whereas EPS biosynthetic machinery is more highly expressed at the swarm periphery, pointing to spatially-distinct roles for each polysaccharide in the maturation of multicellular swarm biofilms (32).

Each of EPS, BPS, and MASC is synthesized by a separate Wzx/Wzy-dependent pathway, with each respective component given the suffix X (exopolysaccharide), B (biosurfactant), or S (spore coat) (32-35). Individual polysaccharide repeat units in such pathways are assembled on the lipid carrier undecaprenyl pyrophosphate (UndPP) at the cytoplasmic leaflet of the inner membrane (IM), followed by processing via a suite of integral IM proteins (36). Repeat units bound to UndPP are first transported across the IM by the Wzx flippase (37-40). UndPP-linked repeats in the periplasmic leaflet of the IM are then polymerized by Wzy (41-43), to modal lengths specified by Wzz/Wzc polysaccharide co-polymerase (PCP) proteins (41). BPS-pathway WzcB is of the PCP-2A class (44) as it contains an attached cytosolic bacterial tyrosine autokinase (BYK) domain $(32,45,46)$. Conversely, EPS- and MASC-pathway WzcX and WzcS (respectively) are of the PCP-2B class as they do not encode a fused BYK domain; instead, these pathways encode standalone WzeX/S BYK proteins $(32,47)$ for association with their cognate WzcX/S PCP. In turn, Wzb bacterial tyrosine phosphatase (BYP) proteins are also encoded to control the phosphorylation state of PCP-2A Wzc proteins and PCP-2B-associated Wze proteins (48). The M. xanthus Wzb BYP (PhpA) has been shown 
to dephosphorylate BYK WzeS as well as the BYK domain of WzcB (49), implicating Wzb in

105

106

107

108

109

110

111

112

113

114

115

MASC and BPS biosynthesis. The cytosolic (de)phosphorylation states of PCP-2A Wzc and PCP-2B-associated Wze proteins control not only polymer modal length modulation, but also secretion of the respective heteropolysaccharide across the OM via the Wza translocon $(50,51)$. A range of activators and inhibitors are known to impact $M$. xanthus EPS biosynthesis (reviewed in (18)), with the Dif chemosensory pathway the most noteworthy (52-54). Positive regulation of EPS production is mediated by (i) the methyl-accepting chemotaxis protein DifA, (ii) the CheW-like coupling protein DifC, (iii) the CheA-like histidine kinase DifE, and (iv) the EpsW response regulator (phosphorylated by DifE) (55-57) Conversely, EPS production is negatively regulated by (i) the DifD response regulator, (ii) the CheC-like phosphatase DifG, and (iii) Nla19, an NtrC-like transcriptional regulator $(54,58)$. Despite these details, the specific functional links between the Dif pathway and the Wzx/Wzy-dependent EPS biosynthesis system have yet to be identified.

While the biosurfactant nature of BPS was previously demonstrated, the mechanism by which it promotes swarm structuration and T4P-dependent spreading was not known (32). Herein, we provide evidence/demonstrate that unlike conventional biosurfactants — which typically function as wetting agents secreted at colony fronts to condition the substratum and promote spreading - a major role of BPS is to change the activation state of the EPS surface glycocalyx. This impacts cell-level and community-scale behaviours leading to altered multicellular outcomes. 


\section{RESULTS}

125

126

127

128

129

130

131

132

133

134

135

136

137

138

139

140

141

142

143

144

145

\section{BPS-deficient M. xanthus cells are hyper-aggregative}

Though BPS ${ }^{-}$and $\mathrm{EPS}^{-}$swarms were previously shown to be compromised for T4Pdependent swarm expansion — with the former elaborating a fuzzy morphology and the latter a smooth phenotype - under nutrient limitation $\mathrm{BPS}^{-}$cells were still able to aggregate and form spore-filled fruiting bodies, similar to WT (but not EPS ${ }^{-}$) swarms (32) (Fig. 1). However, the developmental transition to fruiting bodies for $\mathrm{BPS}^{-}$swarms could take place at lower initial cell densities compared to WT swarms, suggesting that cells may aggregate more efficiently in BPS swarms (32). To specifically probe aggregative differences among $M$. xanthus cell-surface polysaccharide mutants, the real-time ability of cells to auto-aggregate in liquid media was compared, a phenomenon known to be dependent on the presence of cell-surface EPS and an extendable T4P $(22,26,30,33,55,56,58-68)$. While both $\mathrm{EPS}^{-}$and $\mathrm{T}^{-} \mathrm{P}^{-}$cells remained in suspension, $\mathrm{BPS}^{-}$cells rapidly auto-aggregated by the first post-mixing time point (10 min), resulting in faster initial unaided sedimentation relative to WT cells; after $\sim 40 \mathrm{~min}$, WT and $\mathrm{BPS}^{-}$cells in rich media continued to sediment, but at comparable rates, consistent with continued metabolism (Fig. 2A). The same rapid auto-aggregation phenotype at the same postmixing time point (10 min) was observed for $\mathrm{BPS}^{-}$cells (relative to WT) under nonmetabolizing conditions in minimal buffer, with the auto-aggregation levelling off at 40 min (Fig. 2B). Together, these cell-level hyper-aggregation data (i) help explain fruiting body formation for $\mathrm{BPS}^{-}$swarms at lower cell densities (32), (ii) suggest that T4P may indeed be extendable in $\mathrm{BPS}^{-}$cells, and (iii) are consistent with differences in the general surface properties of $\mathrm{BPS}^{-}$cells. 
To directly probe T4P assembly, WT, $\mathrm{BPS}^{-}$and $\mathrm{EPS}^{-}$cells from liquid culture were analyzed via transmission electron microscopy (TEM). As expected, from the poles of WT cells,

149 numerous T4P projections could be observed, including both thin filaments (likely single pili)

150 and thick filaments (likely bundles of pili); the presence of T4P bundles is supported by the

151 observation that at certain points along the thick filament, branching occurred, with the new

152 offshoots resembling thin filaments (Fig. 2C). While no EPS $^{-}$cells were observed with attached

153 T4P projections emanating from a cell pole, thin T4P-like filaments were detected on the grid

154 (Fig. 2C). This may suggest that $\mathrm{EPS}^{-}$cells can still assemble a T4P, but that the presence of

155 cell-surface EPS contributes to strengthening the apparatus. Intriguingly, $\mathrm{BPS}^{-}$cells were

156 observed to extend T4P, but they were not as prevalent as in WT cells; moreover, the T4P

157 filaments detected in $\mathrm{BPS}^{-}$cells were typically shorter than those in WT cells, and not found in

158 presumed thick T4P bundles (Fig. 2C). Thus while $\mathrm{BPS}^{-}$cells can still extrude T4P projections,

159 the assembly of these apparatus appears to be compromised relative to WT cells, helping to

160 explain the deficiency in T4P-dependent motility in $\mathrm{BPS}^{-}$cells (Fig. 1) (32). 
Increased Trypan Blue-retention by $\mathrm{BPS}^{-}$cells is inconsistent with EPS overproduction pathway mutants $\Delta w z c B, \Delta w z c B_{\mathrm{BYK}}, \Delta w z a B$, and $\Delta w z a B \Delta w z c B$ - in which periplasmic BPS polymerization should be permitted but secretion compromised — reproducibly bound more Trypan Blue than WT cells (combined interquartile range of 102-133\% of WT) (Fig. 2D) (32). This dye-retention difference was manifested despite equivalent levels of the same cellassociated EPS sugars detected in WT and BPS ${ }^{-}$cells (32). However, the abovementioned four BPS-pathway mutant strains still bound significantly less Trypan Blue than the $\Delta$ difG strain

170 (interquartile range of 113-202\% of WT) (Fig. 2D). The latter is a mutant in the Dif

171 chemosensory pathway in which EPS production is no longer negatively-regulated, resulting in 172 increased EPS production; this is compared to a $\triangle$ difE strain in which EPS production is

173 downregulated (Fig. 2D) $(55,56,58,70)$. In fact, EPS overproduction does not significantly 174 compromise T4P-dependent swarm spreading relative to a BPS deficiency (Fig. 1B), which 175 severely impairs swarm spreading (32). Taken together with the comparative dye-retention 176 analyses of EPS regulatory mutants (Fig. 2D), these data are consistent with the elevated

177 retention of Trypan Blue by the abovementioned BPS-pathway mutants not being due to EPS 178 overproduction. Instead, this may point to differences in surface properties between WT and $179 \mathrm{BPS}^{-}$cells. 


\section{BPS deficiency decreases the relative cell-surface hydrophobicity of $\mathrm{M}$. xanthus}

181

To probe the physical properties of $\mathrm{WT}$ and $\mathrm{BPS}^{-}$cell surfaces, both strains were subjected to MATH (microbial adhesion to hydrocarbons) testing to probe relative differences in cell-surface hydrophobicity (71). Cells of either strain were resuspended in (aqueous) liquid medium and mixed with the hydrocarbon hexadecane, after which the emulsion was allowed to clear (72). The rationale herein is that the greater the cell-surface hydrophobicity of a particular strain, the more cells removed from suspension through hydrophobic contacts with hexadecane, thus decreasing the turbidity of the suspension (71). Compared to $\mathrm{OD}_{600}$ readings taken before hexadecane addition-and-mixing, significantly fewer WT cells remained in suspension (i.e. lower $\mathrm{OD}_{600}$ ) following emulsion separation compared to $\mathrm{BPS}^{-}$cells (Fig. 2E). These findings do not indicate that WT cells are hydrophobic per se, but rather that the WT cell surface is relatively more hydrophobic compared to that of $\mathrm{BPS}^{-}$cells. Therefore, BPS secretion increases the relative hydrophobicity of the $M$. xanthus cell surface. Moreover, this dataset further supports the designation of BPS as a biosurfactant since biosurfactants have been extensively reported to change the relative cell-surface hydrophobicity of various bacterial cells (73). Finally, the reduced relative cell-surface hydrophobicity of $\mathrm{BPS}^{-}$cells may help explain the higher-than-WT amounts of hydrophilic Trypan Blue binding observed for the $\Delta w z c B$, $\Delta w z c B_{\mathrm{BYK}}, \Delta w z a B$, and $\Delta w z a B \Delta w z c B$ mutants previously described (Fig. 2D) (32). 


\section{BPS secretion is required for EPS surface-fibril formation}

Given the multiple datasets pointing towards fundamental cell-surface differences

200 between WT and BPS $^{-}$cells (Fig. 2A-E), surface morphologies for these strains (as well as EPS

201 cells) were directly visualized via scanning electron microscopy (SEM). Consistent with

202 previous reports, WT cells were shown to be connected via networks of EPS fibrils, while EPS

203 cells lacked any such connections $(16,55,63,74-79)$ (Fig. 2F). Interestingly, while BPS ${ }^{-}$cells

204 still produce EPS (32) (Fig. 2D), no inter-cell fibril networks were observed for this strain (Fig.

205 2F). This may indicate that while EPS by itself is tightly held by individual cells, the secretion

206 of BPS serves to sufficiently destabilize or loosen the cell-surface EPS glycocalyx, thus

207 promoting fibril formation and inter-cell connections. 


\section{EPS glycocalyx destabilization impacts single-cell behaviour}

Since BPS $^{-}$cells are capable of forming fruiting bodies (Fig. 1A) (32), this suggests that $\mathrm{BPS}^{-}$cells can still perform single-cell gliding motility, which is required for efficient fruiting body formation (80). For swarms grown on hard 1.5\% agar, flare projections were observed emanating from the edge of the inoculated spot, a tell-tale sign of gliding motility by $\mathrm{BPS}^{-}$cells (Fig. 1A). By way of severe oblique illumination of the samples, we were also able to visualize the furrow network left behind in the agar by lead gliding cells at the swarm edge (Fig. 1A).

Previously revealed in detail by others using 3D profilometry, these physical depressions in the agar substratum were revealed to be the source of phase-bright trails classically attributed to slime deposition by M. xanthus cells gliding on agar (81). All strains tested produced furrows, indicating that the presence or absence of EPS and/or BPS does not qualitatively impact the formation of these substratum depressions. Moreover (while not possible to distinguish between single cells and cell groups), additional cells were detected following the path of the various furrows (Fig. 1A), supporting the notion of sematectonic stigmergic coordination for the phenomenon of trail following by M. xanthus cells on agar (82). At the single-cell level, the presence of a compacted surface glycocalyx in $\mathrm{BPS}^{-}$cells, or the complete absence of this layer in EPS $^{-}$cells, resulted in faster gliding motility than in WT cells (Fig. 3A). Compared to BPS ${ }^{-}$ or EPS ${ }^{-}$cells, this may indicate that the bulk volume of the destabilized EPS surface layer in WT cells adversely affects gliding efficiency.

We next probed the frequency at which single cells reversed their gliding direction. Cells were imaged at $30 \mathrm{~s}$ intervals for 50 frames. To avoid unintentionally lowering reversal frequency averages (by including cells tracked for a short time in which a reversal may not have yet manifested), we only analyzed cells continuously tracked for 30 or more frames. Cells 
231 deficient in EPS secretion were observed to reverse their gliding direction less frequently

232 compared to WT cells (Fig. 3B), consistent with previous reports of lower reversal frequencies in

233 Dif-pathway mutants in which EPS production is compromised $(68,83)$. Conversely, $\mathrm{BPS}^{-}$cells

234 were found to reverse their gliding direction more frequently than WT cells (Fig. 3B). Together,

235 these data point to not only the general importance of EPS in regulating reversal frequency, but

236 also its "activation state" as determined by the effects of BPS.

238 polymertropism responses of $\mathrm{EPS}^{-}$and $\mathrm{BPS}^{-}$cells. Polymertropism is a gliding motility-

239 dependent process. It is measured via changes of the swarm aspect ratio, i.e. comparisons of

240 changes in "east-west" expansion vs "north-south" expansion on an agar plate in response to the

241 insertion of a small length of tubing between the edge of the agar and the "northern" wall of the

242 Petri dish. The net effect of this agar compression is to align the polymers in the substratum

243 matrix, allowing $M$. xanthus and other bacteria to preferentially spread in the "east-west"

244 direction of the aligned substratum polymers (10,84-86). While no significant differences in

245 polymertropism responses were detected between WT and EPS ${ }^{-}$swarms, BPS ${ }^{-}$swarms

246 demonstrated a remarkably enhanced capacity to spread in the "east-west" direction on

247 compressed agar (Fig. 3C). This is the first known description of a hyper-polymertropic $M$.

248 xanthus strain. While specific cellular factors contributing to the polymertropism response

249 remain poorly understood, our data suggest that the presence of EPS as well as increased gliding

250 speed may contribute to this enhanced "east-west" swarm expansion in response to mechanical

251 changes in the substratum. The secretion of BPS thus affects $M$. xanthus behaviours at multiple

252 levels of biological organization, from entire communities down to single cells. 


\section{BPS secretion is required for cell stratification within swarms}

254

255

256

257

258

259

260

261

262

263

264

265

266

267

268

269

270

271

272

273

274

275

We next sought to probe potential ultrastructural differences in swarm architecture leading to compromised T4P-dependent colony expansion. To highlight internal structures as per a previous report (17), spreading swarms were treated with Ruthenium Red, a polycationic dye that interacts with a range of polyanionic targets (87). This was carried out for swarms of WT, as well as the isogenic $\mathrm{EPS}^{-}, \mathrm{BPS}^{-}$, and $\mathrm{MASC}^{-}$mutant strains, followed by negative-stain TEM of transversely-cut sections near the swarm edge (Fig. 4, inset). This resulted in electrondense labelling of the $M$. xanthus cell surface in the absence of EPS, BPS, or MASC secretion (Fig. 4). These analyses also revealed pronounced horizontal electron-dense structures separating stratified layers of WT and $\mathrm{MASC}^{-}$cells, with such structures largely absent in $\mathrm{BPS}^{-}$ swarms and nonexistent in EPS ${ }^{-}$swarms (Fig. 4). Vertical striations of this electron-dense material - connecting horizontal electron-dense structures above and below to form a selfcontained so-called "microchannel" — were not detected (Fig.4). The rod-shaped cells within the layered WT and $\mathrm{MASC}^{-}$swarms, as well as the more irregularly-packed $\mathrm{BPS}^{-}$swarm, were highly aligned along their long axes in the direction of migration, resulting in the round appearance of cells in the cross sections (Fig. 4). Cells in $\mathrm{BPS}^{-}$swarms were also more closelypacked together compared to either WT, MASC ${ }^{-}$, or $\mathrm{EPS}^{-}$swarms (Fig. 4).

Higher-magnification views of the horizontal electron-dense ribbons revealed these structures to be of heterogeneous composition; in addition to wispy material which could represent one or more accumulated polysaccharide species, enrichments of individual OMVs as well as OMV chains were also observed at these sites (Fig. 4).

Taken together, these data suggest that the horizontal electron-dense structures (Fig. 4) are not required for nematic alignment of cells in these swarms. Furthermore, the close packing 
276 of cells in $\mathrm{BPS}^{-}$swarms is consistent with $\mathrm{BPS}^{-}$cells being more highly aggregative (Fig.

277 2A,B), forming fruiting bodies at lower initial cell densities (32), and displaying more compact

278 surface EPS glycocalyces lacking fibril structures (Fig. 2F). Finally, the accumulation of various

279 types of material at these horizontal electron-dense ribbons (Fig. 4) raises the possibility that

280 these striations are, in essence, exclusion boundaries between different layers of $M$. xanthus cells

281 within a swarm. Further comment on the nature of these horizontal electron-dense structures can

282 be found in the Discussion below. 


\section{DISCUSSION}

Originally referred to as "slime fibrils/fibers", sinewy structures connecting the surfaces of clustered $M$. xanthus cells have been known for $>40$ years $(88,89)$, with the only known requirement being the presence of the cell-surface EPS glycocalyx $(55,63,74,75,78)$. Given the phenotypic, biochemical, and biophysical data presented herein, we propose that it is not simply the presence of cell-surface EPS that is required to mediate these inter-cell connections in M. xanthus, but rather the activation state of the EPS glycocalyx induced by the effects of secreted BPS.

Unfortunately, confusion exists throughout the scientific literature on the use of the abbreviation "EPS", especially for M. xanthus research. Various laboratories (including ours) use "EPS" to specifically denote the principal matrix polysaccharide assembled and secreted via the WzxX-WzyX-WzcX-WzeX-WzaX proteins (32, 33, 65). However, "EPS" has also been used to non-specifically refer to diverse secreted polysaccharides (i.e. "exopolysaccharides"). For many bacteriologists, "EPS" has even more broadly come to signify "extracellular polymeric substances", a term that has come to encompass not only secreted polysaccharides, but also polypeptides and polynucleotides. Given theses various uses, particular attention is required when interpreting and comparing findings across diverse publications.

The data presented herein provide complementary insights into the nature of T4Pdependent group motility in $M$. xanthus swarm biofilms, as they implicate the importance of BPS on several levels. Type IV pili in M. xanthus are known to interact with cell-surface EPS, which is how M. xanthus cells in rafts are proposed to move together, i.e. a T4P from a given cell is able to interact with the surface EPS layer on an adjacent cell, triggering T4P retraction, close cell-cell association, and group movement (26). Previously, single cells were found to move via 
T4P extension and retraction on polystyrene surfaces, but only in the presence of a viscous solution of $1 \%$ methylcellulose $(90,91)$. To what exactly then does a $M$. xanthus T4P bind? Though $\mathrm{BPS}^{-}$cells can extend a T4P (Fig. 2C), these apparatus were typically shorter, thinner, and less prevalent than those in WT cells, and it is not known if pili from $\mathrm{BPS}^{-}$cells are still able to interact with the "non-activated" EPS on adjacent BPS ${ }^{-}$cells. Simplistically, the T4P may

311 need to get stuck within the activated EPS matrix in WT cells, something which might not be 312 possible in $\mathrm{BPS}^{-}$cells. Alternatively, if unable to bind, this could signify that a specific motif on 313 "activated" EPS needs to be recognized by the T4P, and that this motif is not exposed on the 314 glycocalyx of BPS ${ }^{-}$cells. Rather than the "stuck-in-goo" hypothesis, additional evidence supports the latter theory. Specifically, that (i) T4P retraction can be triggered by amine-

316 containing polysaccharides (26), and (ii) single-cell T4P motility is possible in an aqueous

317 microfluidic channel atop glass functionalized with a molecular coating of

318 carboxymethylcellulose (92). The latter principal is analogous to that used for chitosan coatings

319 in microfluidic chambers to test single-cell gliding motility on glass substrata $(24,93)$.

In addition, BPS secretion alters the fundamental properties of the M. xanthus cell

321 surface, impacting numerous processes. Importantly, an imbalance in the EPS:BPS secretion

322 ratio in a given cell can alter surface adhesiveness, directly influencing spatiotemporal cell-cell

323 interaction dynamics, and by extension, swarm biofilm architecture. A greater proportion of

324 EPS:BPS in $\triangle w z a B$ cells (i.e. WT levels of EPS, no BPS) results in swarms displaying a fuzzy

325 morphology on soft agar (32) (Fig. 1A). Similarly, robustly increasing the production of EPS (in

$326 \Delta$ difG cells) may dilute the effect of BPS, resulting in a similar fuzzy swarm morphology (Fig.

327 1A), albeit with a larger surface area (Fig. 1B). 
However, BPS ${ }^{-}$cell traits such as increased gliding speed and more frequent reversals

329 (relative to WT) are more difficult to interpret. Given that EPS $^{-}$cells are not aggregative, the apparent increased "stickiness" of BPS" cells (and presumed stronger association with the substratum) is not believed to lead to appreciably more efficient substratum-coupling of the Agl-

332 Glt machinery. As the EPS glycocalyx is likely more compacted in BPS $^{-}$cells, and completely

333 absent in EPS $^{-}$cells, we speculate that the bulk volume occupied by the BPS-activated EPS

334 surface layer in WT cells results in suboptimal surface coupling of the gliding machinery.

335 Conversely, overall increased vs. decreased stickiness of $\mathrm{BPS}^{-}$vs. $\mathrm{EPS}^{-}$cells (respectively) may

336 indicate a role for mechanical feedback from physical interactions with the substratum

337 influencing properties of the Agl-Glt apparatus at bFA sites and/or the Frz chemosensory system that governs polarity reversals within the cell (94), potentially affecting reversal frequency. The combined effects of increased gliding speed and potential differences in bFA stability and/or Frz system activity may also help explain the hyper-polymertropism observed for $\mathrm{BPS}^{-}$cells.

342 presented herein provides important independent support for the overall concept of leading-edge "microchannels" reported by Berleman and colleagues (17). Differences in the numbers of cells contained within layer/channel structures could be attributable to minor variations in initial

345 swarm inoculation (volume, cell density, etc.). However, we remain skeptical of the notion that 346 the Ruthenium Red-labelled structures are mainly composed of EPS. Ruthenium Red is a

347 polycationic dye with a well-documented propensity for binding to a range of anionic targets 348 (87). Originally used as a highly-effective labelling agent for pectin (a galacturonic acid-rich 349 polysaccharide), the dye has since been shown to also bind other anionic polysaccharides, phospholipids, DNA, and proteins $(87,95-98)$. Though a chemical structure has yet to be 
351 determined, the composition of $M$. xanthus EPS has been studied across four publications. In

352 total, arabinose, galactose, $N$-acetyl-galactosamine, glucose, glucosamine, $N$-acetyl-glucosamine,

353 mannose, $N$-acetyl-mannosamine, rhamnose, and xylose sugars have been reported (32, 77, 99 ,

354 100). However, none of these reported EPS sugars carry a net-negative charge that would favour

355 Ruthenium Red binding; this has lead us to question whether the distinct horizontal ribbons we

356 detected within WT and MASC ${ }^{-}$swarms (Fig. 4), as well as the walls of self-enclosed so-called

357 "microchannel" structures at the WT swarm edge (17), are indeed composed of M. xanthus EPS.

Of note, extracellular DNA (eDNA) has been previously detected in M. xanthus biofilms

and shown to bind secreted polysaccharides as well as strengthen the extracellular matrix (101).

Moreover, we have herein detected the accumulation of OMVs and OMV chains at the

361 Ruthenium Red-stained layers, material which by definition contains phospholipids as well as

362 phosphate groups linked to the Lipid A motif of its LPS (102) (Fig. 4). In addition to

363 polysaccharide, the $M$. xanthus extracellular matrix is also abundant in protein species of largely

364 unknown functions $(77,103)$. Most intriguingly, BPS may be a strong candidate for the

365 principal Ruthenium Red-labelled substance detected in the mid-swarm horizontal ribbons

366 reported herein (Fig. 4) as well as the leading-edge enclosed channel structures previously

367 reported (17). Consider that the BPS polymer is an acidic heteropolysaccharide built of

368 repeating tetrasaccharide units; each tetrasaccharide repeat contains a proximal $N$-acetyl-D-

369 mannosamine, followed by three distal anionic $N$-acetyl-D-mannuronic acid sugars, with the first

370 three sugars of each repeat being randomly acetylated (32). Furthermore, pronounced

371 Ruthenium Red-labelled horizontal striations were not detected in $\mathrm{BPS}^{-}$swarms (Fig. 4). In

372 addition, compositional analysis of cell-associated sugars as well as surface-active testing of

373 culture supernatants suggest that BPS is not bound to the cell surface and is instead secreted into 
374 the extracellular milieu (32). The combined effect of a sheet of EPS glycocalyces from adjacent

375 cells could thus be to electrostatically and/or sterically exclude secreted anionic BPS and

376 concentrate it at EPS-free zones between cell layers. It may then be in these levels of a swarm

377 where BPS may fully activate (destabilize) the EPS of adjoining cells, allowing for efficient

378 T4P-mediated swarm expansion. This could also explain why no Ruthenium Red-stained

379 structures could be detected in EPS $^{-}$swarms (Fig. 4) (17), i.e. the absence of EPS resulted in no

380 exclusion boundaries at which BPS could accumulate. In this manner, the lumen of swarm-edge

381 microchannels would still contain EPS material, but the surrounding Ruthenium Red-binding

382 wall structures would contain BPS. Ultimately, BPS-dependent stratification in swarm biofilms

383 appears to play an important role in community organization and expansion.

384 Our data may also shed light on findings regarding the proposed effect of the Wzb

385 (PhpA) tyrosine phosphatase on M. xanthus EPS production (49). Mori and colleagues reported

386 that a mutant lacking this Wzb tyrosine phosphatase possessed higher levels of phosphorylated

387 (i) BYK protein WzeS (BtkA) and (ii) the BYK domain-containing WzcB (BtkB) (49). These

388 proteins are now known to be a part of the MASC and BPS assembly pathways, respectively (32,

389 33, 47). Wzb-deficient cells also exhibited faster auto-aggregation in cuvettes compared to WT

390 cells, and were able to aggregate earlier in development resulting in faster fruiting body

391 formation (49). Finally, the amount of Trypan Blue dye bound by Wzb-deficient cells was $134 \%$

392 that of WT cells (49). Accounting for these and other data, the authors concluded that PhpA may

393 have a negative regulatory effect on EPS biosynthesis (49). However, based on (i) the

394 demonstrated dephosphorylation of BPS-pathway WzcB by this Wzb tyrosine phosphatase (49),

395 (ii) the faster auto-aggregation of $\mathrm{BPS}^{-}$cells (Fig. 2A,B), (iii) the more efficient formation of

396 fruiting bodies by $\mathrm{BPS}^{-}$swarms (32), and (iv) the marginally higher amount of Trypan Blue 
397 bound by BPS $^{-}$cells relative to WT (Fig. 2D) (32), the findings for Wzb-deficient vegetative

398 cells are more in line with a deficiency in BPS production rather than an increase in EPS

399 production. With respect to direct effects of Wzb on the EPS biosynthesis pathway, it remains to

400 be seen whether the Wzb tyrosine phosphatase (which already acts on WzcB and WzeS) also

401 acts on the recently-identified WzeX BYK shown to be essential for EPS biosynthesis (32). To

402 date, the manner by which the Dif chemosensory pathway regulates EPS production is unknown

403 (18). Nonetheless, regulation of the putative phosphorylation state of WzeX is an attractive

404 target for understanding changes in EPS levels during the M. xanthus lifecycle. 


\section{MATERIALS AND METHODS}

406

407

408

409

410

411

412

413

414

415

416

417

418

419

420

421

422

423

424

425

426

427

\section{Bacterial Cell Culture}

The $M$. xanthus strains used in this study are listed in Table 1 . They were grown and maintained at $32{ }^{\circ} \mathrm{C}$ on Casitone-yeast extract (CYE) agar plates or in CYE liquid medium at 32 ${ }^{\circ} \mathrm{C}$ on a rotary shaker at $220 \mathrm{rpm}$. The Escherichia coli strains used for plasmid construction were grown and maintained at $37^{\circ} \mathrm{C}$ on LB agar plates or in LB liquid medium. Plates contained $1.5 \%$ agar (BD Difco).

\section{Phenotypic Analysis}

Exponentially-growing cells were harvested and resuspended in TPM buffer (10 mM Tris- $\mathrm{HCl}, \mathrm{pH} 7.6,8 \mathrm{mM} \mathrm{MgSO}_{4}$ and $1 \mathrm{mM} \mathrm{KH}_{2} \mathrm{PO}_{4}$ ) at the final concentration of $\mathrm{OD}_{600} 5.0$ for gliding, T4P-dependent expansion, and developmental assays. This cell suspension (5 $\mu \mathrm{L})$ was spotted onto CYE 1.5\% agar, CYE 0.5\% agar, or CF 1.5\% agar for gliding flare, T4P-dependent swarm expansion, or developmental (i.e. fruiting body formation) analysis, respectively. Plates were incubated at $32{ }^{\circ} \mathrm{C}$ for $30 \mathrm{~h}$ for gliding flares, $72 \mathrm{~h}$ for T4P-dependent swarm expansion, and $75 \mathrm{~h}$ for fruiting body formation, then photographed with an Olympus SZX16 stereoscope with UC90 4K camera. Gliding flares were imaged using the $2 \times$ objective at $8 \times$ zoom, using linear colour, with illumination control wheel set halfway between the brightfield cartridge and the open slot on the illumination wheel. For T4P-dependent motility, swarms were imaged using the $0.5 \times$ objective at $1 \times$ zoom, using linear colour and darkfield illumination. For fruiting bodies, structures were imaged using the $0.5 \times$ objective at $2 \times$ zoom, using high-quality colour and oblique illumination. 


\section{Transmission Electron Microscopy}

For T4P visualization, a $50 \mu \mathrm{L}$ drop of overnight liquid culture was transferred to a copper grid and incubated at ambient temperature for $5 \mathrm{~min}$. Grids were then dried with bibulous paper, stained with 3\% PTA ( $\mathrm{pH}$ 6.0) (Mecalab) for $2 \mathrm{~s}$, and dried again with bibulous paper. For swarm biofilm cross-sections, swarm samples were fixed in $2.5 \%$ glutaraldehyde in cacodylate buffer at $\mathrm{pH} 7.4$ with $0.2 \mathrm{M}$ sucrose overnight and then washed three times with cacodylate buffer. Then post-fixed in $1.33 \%$ osmium tetroxide in Collidine buffer ( $\mathrm{pH} 7.4$ ) for 1 $\mathrm{h}$ and stained with $5 \mathrm{mM}$ Ruthenium Red for $1 \mathrm{~h}$ at ambient temperature. After dehydration by successive passages through $25,50,75,95 \%$ and $100 \%$ (twice) solutions of ethanol in water (for $30 \mathrm{~min}$ each), samples were immersed for $16-18 \mathrm{~h}$ in Spurr:acetone $(1: 1 \mathrm{v} / \mathrm{v})$. Samples were then embedded in Spurr resin (TedPella) before incubation at $60-65^{\circ} \mathrm{C}$ for $20-30 \mathrm{~h}$. After polymerization, samples were sectioned $(90-150 \mathrm{~nm})$ using an ultramicrotome (LKB Brooma 2128 Ultratome). Sections were collected on formvar / carbon-coated copper 200-mesh grids. Samples were stained with 5\% uranyl acetate in 50\% ethanol for 15 minutes followed by lead citrate for 5 minutes. Imaging for T4P and swarm biofilm cross-sections was carried out using a Hitachi H-7100 transmission electron microscope with AMT XR-111 camera.

\section{Scanning Electron Microscopy}

Glass coverslip discs were first washed in $100 \% \mathrm{EtOH}$ for $1 \mathrm{~h}$ and left to dry at RT under sterile conditions. The cleaned discs were immersed for $1 \mathrm{~h}$ at RT in $0.01 \%$ poly-L-lysine solution and allowed to dry. Discs were placed one per well in a 24-well polystyrene cellrepellent plate and overlaid with $2 \mathrm{~mL}$ of overnight CYE bacterial cultures. Plates were then covered, sealed with Parafilm, and incubated overnight with shaking at $32^{\circ} \mathrm{C}$. After incubation, 
451 the media was removed and the cells attached to the coverslips were fixed in $1 \mathrm{~mL}$ of $2.5 \%$

452 glutaraldehyde in $0.1 \mathrm{M}$ cacodylate buffer $(\mathrm{pH}$ 7.4) for at least $1 \mathrm{~h}$ and washed three times in 1

$453 \mathrm{~mL}$ of $0.2 \mathrm{M}$ cacodylate buffer for $5 \mathrm{~min}$. After post-fixation in $500 \mu \mathrm{L}$ of $1.33 \%$ osmium

454 tetroxide (in $0.2 \mathrm{M}$ cacodylate buffer) for $1 \mathrm{~h}$, bacteria were dehydrated with increasing ethanol

455 concentrations $(25,50,75,95$ and 100\%). From the $100 \%$ EtOH bath, coverslips were critical-

456 point-dried using $\mathrm{CO}_{2}$ (Leica EM ACE600), coated with $3 \mathrm{~nm}$ gold/palladium (Leica CPD300)

457 and examined with a JEOL JSM-7400F scanning electron microscope (3 kV-LEI detector).

458

\section{Single-Cell Gliding Motility Analysis}

For phase-contrast microscopy on agar pads, cells from exponentially-growing cultures

461 were sedimented and resuspended in TPM buffer (OD 600 0.7), spotted ( $3 \mu \mathrm{L})$ on a glass

462 coverslip, and overlaid with a $1.5 \%$ agar pad prepared with TPM buffer. For motility analysis,

463 cells were left to adhere for 5 min prior to imaging at $32^{\circ} \mathrm{C}$. Images were obtained using an

464 Axio Observer 7 microscope, with a Plan Apochromat 40× 1.3 oil objective VIS-IR M27 (for

465 total magnification 400×), an Axiocam 512 as camera, and a TL LED as light source (Zeiss).

466 Images were taken at $30 \mathrm{~s}$ intervals. The microscope was operated using the Zen 2.6 Pro software

467 suite (Zeiss).

Prior to analysis, image stacks were treated in FIJI as follows to optimize tracking: Step

469 1: Enhance Contrast (0.3\%), Normalize, Process All Slices. Step 2: Subtract Background

470 (Rolling ball radius of 15.0 pixels, Light background, Process all slices). Step 3: Image

471 alignment in stack via StackReg (Translation) plug-in. Cell gliding speeds were then calculated

472 using the MicrobeJ module for FIJI (104): Step 1: Under the Bacteria tab, Tracking Parameters

473 were adjusted (Max Entropy, Medial Axis, Area: 18-800, Length: 10-max, Width: 1.5-max), 
474 with only cells tracked for a minimum lifespan of 20 frames used for analysis. Step 2:

475 Automatically-detected objects were manually curated to remove instances of object merging,

476 background artifact detection, and reference cell switching, followed by comparison of Velocity

477 Means (pixels/frame). Step 3: Gliding speeds were converted to " $\mu \mathrm{m} / \mathrm{min}$ ". Reversals of gliding

478 direction for these tracked cells were manually counted, with a minimum displacement of $\sim 75 \%$

479 of cell length considered a reversal.

480

\section{Polymertropism Testing}

Aspect ratio (AR) vs. time analyses were modified from a published report (84) and were performed as previously described (85). Cells of $M$. xanthus (grown in CYE at $28{ }^{\circ} \mathrm{C}$ to $\sim 5 \times$

$48410^{8}$ cells $\left./ \mathrm{mL}\right)$ were sedimented $(4000 \times g, 10 \mathrm{~min})$, then resuspended in CYE broth to $5 \times 10^{9}$

485 cells $/ \mathrm{mL}$, and used to inoculate $(4 \mu \mathrm{L})$ compressed and uncompressed round $85 \mathrm{~mm}$ CTTYE 486 agar plates. An 1 cm length of $5.56 \mathrm{~mm}$ outer-diameter Tygon tubing was inserted against the 487 plate wall to compress the agar (84), with cells on these plates inoculated $43 \mathrm{~mm}$ from the 488 inserted tubing. Following incubation at $30^{\circ} \mathrm{C}$ for $24,52,90,120$, and $144 \mathrm{~h}$, colony perimeters 489 were marked at each interval. The AR of each swarm was then calculated for each time point by 490 taking the quotient of the colony width and colony height; a round swarm will produce an AR 491 near-or-equal to one, whereas an elongated swarm will produce an AR $>1$. For each replicate 492 dataset, linear best-fit lines were plotted, followed by determination of the slope (i.e. AR/time). 493 Average slope values were calculated for each strain and normalized as a percentage of the 494 AR/time for the WT strain. 
Auto-Aggregation Testing

Using a modified version of an auto-aggregation protocol (60), overnight $M$. xanthus

cultures $(10 \mathrm{~mL})$ were sedimented in $15 \mathrm{~mL}$ conical tubes $(4000 \times g, 5 \mathrm{~min})$, followed by

500

resuspension of pellets in TPM buffer $(10 \mathrm{~mL})$ and $\mathrm{OD}_{600}$ determination using disposable

501

cuvettes. Specific resuspension volumes were aspirated and sedimented in a microfuge tube

$502(4000 \times g, 5 \mathrm{~min})$; pellets were resuspended in $1 \mathrm{~mL} \mathrm{CYE}$ broth or TPM buffer to a final OD 600

of 0.5 , followed by transfer to a polystyrene spectrophotometer cuvette. Samples were

vigorously aspirated/ejected in the cuvette for 10 s using a p200 micropipette, followed by

505

immediate reading of the $\mathrm{OD}_{600}(t=0)$. Subsequent $\mathrm{OD}_{600}$ readings were obtained at $10 \mathrm{~min}$

507 determined at $t=0$ for each sample.

\section{Cell-Surface Hydrophobicity Testing}

To analyze relative differences in cell-surface hydrophobicity, we employed a modified

511 version of the classic microbial adhesion to hydrocarbons (MATH) assay $(71,72)$. Based on the

512 OD $_{600}$ of $M$. xanthus overnight cultures (12.5 mL CYE) measured via NanoDrop 2000c

513 spectrophotometer (Thermo), sufficient culture volume was removed, sedimented $(6000 \times g, 5$

$514 \mathrm{~min}$ ) in $2 \mathrm{~mL}$ conical tubes, followed by pellet resuspension in $4 \mathrm{~mL}$ fresh CYE medium via

515 using a p1000 micropipette to a final $\mathrm{OD}_{600}$ of 1.0. The $\mathrm{OD}_{600}$ of the equilibrated $4 \mathrm{~mL}$

516 resuspensions (i.e. Mix 1) was read in a quartz cuvette. Cell suspensions were then transferred to

517 a new $15 \mathrm{~mL}$ conical tube using a p1000 micropipette, mixed via vortex (maximum speed, $20 \mathrm{~s}$ ),

518 then transferred back to the quartz cuvette for $\mathrm{OD}_{600}$ determination (i.e. Mix 2); this step was

519 performed as an internal control to ensure that downstream changes in OD 600 were not simply 
520 due to further mixing of the sample, particularly for hyper-aggregative strains. Samples were

521 returned via aspiration with a p1000 micropipette to the same $15 \mathrm{~mL}$ conical tube, followed by

522 addition of $300 \mu \mathrm{L}$ hexadecane (Sigma). To generate emulsions, cell-hydrocarbon mixtures

523 were blended via vortex (maximum speed, $20 \mathrm{~s}$ ), then rapidly transferred back to the quartz

524 cuvette using a p1000 micropipette (i.e. Mix 3). The $\mathrm{OD}_{600}$ of this resuspension was

525 immediately determined $(t=0)$, followed by readings at 5 min intervals for the next three data

526 points. After the initial 15 min of monitoring, emulsion separation was further monitored at 10

527 min intervals to a final monitoring time of 65 min. All OD 600 readings were normalized to the

528 initial $\mathrm{OD}_{600}$ determined for samples at the "Mix 1" stage of processing.

\section{Trypan Blue Dye Retention}

Trypan Blue dye-retention analysis was performed as previously described (32). In brief,

532 cells grown overnight in CYE cultures were resuspended to $\mathrm{OD}_{600} 1.0$ in TPM. Resuspended

533 cells or a cell-free blank $(900 \mu \mathrm{L})$ were added together with Trypan Blue stock solution $(100 \mu \mathrm{L})$

534 to a microfuge tube, then briefly pulsed (1 s) on a vortex mixer. Samples were incubated at room

535 temperature, in an aluminum foil-covered tube rack, on a rocker platform $(1 \mathrm{~h})$ to permit dye

536 binding by the cells. Samples were then sedimented $(16000 \times g, 5 \mathrm{~min})$, followed by transfer of

537 the top $900 \mu \mathrm{L}$ of blank or clarified supernatant to a disposable spectrophotometer cuvette.

538 Using the cell-free "TPM + Trypan Blue" sample, the spectrophotometer was blanked (585 $\mathrm{nm})$.

539 For each clarified supernatant, the absorbance at the same wavelength $\left(\mathrm{A}_{585}\right)$ was determined.

540 Absorbance values were then normalized to A585 for the WT sample. 


\section{ACKNOWLEDGEMENTS}

542 The authors would like to thank (i) Éric Déziel for insightful discussions and

543 troubleshooting regarding hydrophobicity testing and (ii) Philippe Constant for valuable input on

544 biostatistics. A Discovery operating grant (RGPIN-2016-06637) from the Natural Sciences and

545 Engineering Research Council of Canada and a Discovery Award (2018-1400) from the Banting

546 Research Foundation fund work in the lab of S.T.I. as well as studentships for F.S. and N.Y.J.;

547 both are also recipients of graduate studentships from the PROTEO research network. The

548 funders had no role in study design, data collection and interpretation, or the decision to submit

549 the work for publication. 
551

552

553

554

555

556

557

558

559

560

561

562

563

564

565

566

567

568

569

570

571

572

573

574

575

576

577

578

579

580

581

582

\section{REFERENCES}

1. Costerton JW, Geesey G, Cheng KJ. 1978. How bacteria stick. Sci. Am. 238:86-95.

2. O'Toole G, Kaplan HB, Kolter R. 2000. Biofilm formation as microbial development. Annu. Rev. Microbiol. 54:49-79.

3. Zhang Y, Ducret A, Shaevitz J, Mignot T. 2012. From individual cell motility to collective behaviors: insights from a prokaryote, Myxococcus xanthus. FEMS Microbiol. Rev. 36:149-164.

4. Limoli DH, Jones CJ, Wozniak DJ. 2015. Bacterial extracellular polysaccharides in biofilm formation and function. Microbiol. Spectr. 3.

5. Monds RD, O'Toole GA. 2009. The developmental model of microbial biofilms: ten years of a paradigm up for review. Trends Microbiol. 17:73-87.

6. Van Gestel J, Vlamakis H, Kolter R. 2015. Division of labor in biofilms: the ecology of cell differentiation, p. 67-97, Microbial Biofilms.

7. Konovalova A, Petters T, Søgaard-Andersen L. 2010. Extracellular biology of Myxococcus xanthus. FEMS Microbiol. Rev. 34:89-106.

8. Islam ST, Mignot T. 2015. The mysterious nature of bacterial surface (gliding) motility: a focal adhesion-based mechanism in Myxococcus xanthus. Semin. Cell Dev. Biol. 46:143154.

9. Faure LM, Fiche J-B, Espinosa L, Ducret A, Anantharaman V, Luciano J, Lhospice S, Islam ST, Tréguier J, Sotes M, Kuru E, Van Nieuwenhze MS, Brun Y, Théodoly O, L A, Nollmann M, Mignot T. 2016. The mechanism of force transmission at bacterial focal adhesion complexes. Nature 539:530-535.

10. Islam ST, My L, Jolivet NY, Belgrave AM, Fleuchot B, Brasseur G, Faure LM, Sharma G, Lemon DJ, Saïdi F, Fiche J-B, Bratton BP, Singer M, Garza AG, Nollmann M, Shaevitz JW, Mignot T. 2020. CglB adhesins secreted at bacterial focal adhesions mediate gliding motility. bioRxiv:2020.2007.2022.216333.

11. Wu SS, Kaiser D. 1995. Genetic and functional evidence that Type IV pili are required for social gliding motility in Myxococcus xanthus. Mol. Microbiol. 18:547-558.

12. Chang Y-W, Rettberg LA, Treuner-Lange A, Iwasa J, Søgaard-Andersen L, Jensen GJ. 2016. Architecture of the type IVa pilus machine. Science 351:aad2001-2001aad2001-2007.

13. Kaiser D, Warrick H. 2014. Transmission of a signal that synchronizes cell movements in swarms of Myxococcus xanthus. Proc. Natl. Acad. Sci. USA. 
14. Curtis PD, Taylor RG, Welch RD, Shimkets LJ. 2007. Spatial organization of Myxococcus xanthus during fruiting body formation. J. Bacteriol. 189:9126-9130.

15. Copenhagen K, Alert R, Wingreen NS, Shaevitz JW. 2020. Topological defects induce layer formation in Myxococcus xanthus colonies. arXiv.

16. Remis JP, Wei D, Gorur A, Zemla M, Haraga J, Allen S, Witkowska HE, Costerton JW, Berleman JE, Auer M. 2013. Bacterial social networks: structure and composition of Myxococcus xanthus outer membrane vesicle chains. Environ. Microbiol. 16:598-610.

17. Berleman JE, Zemla M, Remis JP, Liu H, Davis AE, Worth AN, West Z, Zhang A, Park H, Bosneaga E, van Leer B, Tsai W, Zusman DR, Auer M. 2016.

Exopolysaccharide microchannels direct bacterial motility and organize multicellular behavior. ISME J.

18. Pérez-Burgos M, Søgaard-Andersen L. 2020. Biosynthesis and function of cell-surface polysaccharides in the social bacterium Myxococcus xanthus. Biol. Chem. (advance online):n/a.

19. Kottel RH, Bacon K, Clutter D, White D. 1975. Coats from Myxococcus xanthus: characterization and synthesis during myxospore differentiation. J. Bacteriol. 124:550-557.

20. Wartel M, Ducret A, Thutupalli S, Czerwinski F, Le Gall A-V, Mauriello EMF, Bergam P, Brun YV, Shaevitz J, Mignot T. 2013. A versatile class of cell surface directional motors gives rise to gliding motility and sporulation in Myxococcus xanthus. PLoS Biol. 11:e1001728.

21. Fink JM, Zissler JF. 1989. Defects in motility and development of Myxococcus xanthus lipopolysaccharide mutants. J. Bacteriol. 171:2042-2048.

22. Bowden MG, Kaplan HB. 1998. The Myxococcus xanthus lipopolysaccharide O-antigen is required for social motility and multicellular development. Mol. Microbiol. 30:275-284.

23. Pérez-Burgos M, García-Romero I, Jung J, Valvano MA, Søgaard-Andersen L. 2019. Identification of the lipopolysaccharide O-antigen biosynthesis priming enzyme and the Oantigen ligase in Myxococcus xanthus: critical role of LPS O-antigen in motility and development. Mol. Microbiol. 112:1178-1198.

24. Ducret A, Valignat M-P, Mouhamar F, Mignot T, Theodoly O. 2012. Wet-surfaceenhanced ellipsometric contrast microscopy identifies slime as a major adhesion factor during bacterial surface motility. Proc. Natl. Acad. Sci. USA 109:10036-10041.

25. Ducret A, Fleuchot B, Bergam P, Mignot T. 2013. Direct live imaging of cell-cell protein transfer by transient outer membrane fusion in Myxococcus xanthus. eLife 2:e00868. 
26. Li Y, Sun H, Ma X, Lu A, Lux R, Zusman D, Shi W. 2003. Extracellular polysaccharides mediate pilus retraction during social motility of Myxococcus xanthus. Proc. Natl. Acad. Sci. USA. 100:5443-5448.

27. Palsdottir H, Remis JP, Schaudinn C, O'Toole E, Lux R, Shi W, McDonald KL, Costerton JW, Auer M. 2009. Three-dimensional macromolecular organization of cryofixed Myxococcus xanthus biofilms as revealed by electron microscopic tomography. J. Bacteriol. 191:2077-2082.

28. Smaldone GT, Jin Y, Whitfield DL, Mu AY, Wong EC, Wuertz S, Singer M. 2014. Growth of Myxococcus xanthus in continuous-flow-cell bioreactors as a method for studying development. Appl. Environ. Microbiol. 80:2461-2467.

29. Hu W, Lux R, Shi W. 2013. Analysis of exopolysaccharides in Myxococcus xanthus using confocal laser scanning microscopy, p. 121-131. In Delcour AH (ed.), Bacterial Cell Surfaces: Methods and Protocols. Humana Press, Totowa, NJ.

30. Hu W, Wang J, McHardy I, Lux R, Yang Z, Li Y, Shi W. 2012. Effects of exopolysaccharide production on liquid vegetative growth, stress survival, and stationary phase recovery in Myxococcus xanthus. J. Microbiol. 50:241-248.

31. Wang J, Hu W, Lux R, He X, Li Y, Shi W. 2011. Natural transformation of Myxococcus xanthus. J. Bacteriol. 193:2122-2132.

32. Islam ST, Vergara Alvarez I, Saïdi F, Guiseppi A, Vinogradov E, Sharma G, Espinosa L, Morrone C, Brasseur G, Guillemot J-F, Benarouche A, Bridot J-L, Ravicoularamin G, Cagna A, Gauthier C, Singer M, Fierobe H-P, Mignot T, Mauriello EMF. 2020. Modulation of bacterial multicellularity via spatio-specific polysaccharide secretion. PLOS Biol. 18:e3000728.

33. Pérez-Burgos M, García-Romero I, Jung J, Schander E, Valvano MA, SøgaardAndersen L. 2020. Characterization of the exopolysaccharide biosynthesis pathway in Myxococcus xanthus. J. Bacteriol.:JB.00335-00320.

34. Pérez-Burgos M, García-Romero I, Valvano MA, Søgaard-Andersen L. 2020. Identification of the Wzx flippase, Wzy polymerase and sugar-modifying enzymes for spore coat polysaccharide biosynthesis in Myxococcus xanthus. Mol. Microbiol. 113:11891208.

35. Islam ST, Lam JS. 2014. Synthesis of bacterial polysaccharides via the Wzx/Wzydependent pathway. Can. J. Microbiol. 60:697-716.

36. Islam ST, Taylor VL, Qi M, Lam JS. 2010. Membrane topology mapping of the Oantigen flippase (Wzx), polymerase (Wzy), and ligase (WaaL) from Pseudomonas aeruginosa PAO1 reveals novel domain architectures. mBio 1:e00189-00110.

37. Liu D, Cole RA, Reeves PR. 1996. An O-antigen processing function for Wzx (RfbX): a promising candidate for O-unit flippase. J. Bacteriol. 178:2102-2107. 
38. Islam ST, Fieldhouse RJ, Anderson EM, Taylor VL, Keates RAB, Ford RC, Lam JS. 2012. A cationic lumen in the Wzx flippase mediates anionic O-antigen subunit translocation in Pseudomonas aeruginosa PAO1. Mol. Microbiol. 84:1165-1176.

39. Islam ST, Eckford PDW, Jones ML, Nugent T, Bear CE, Vogel C, Lam JS. 2013. Proton-dependent gating and proton uptake by Wzx support O-antigen-subunit antiport across the bacterial inner membrane. mBio 4:e00678-00613.

40. Islam ST, Lam JS. 2013. Wzx flippase-mediated membrane translocation of sugar polymer precursors in bacteria. Environ. Microbiol. 15:1001-1015.

41. Woodward R, Yi W, Li L, Zhao G, Eguchi H, Sridhar PR, Guo H, Song JK, Motari E, Cai L, Kelleher P, Liu X, Han W, Zhang W, Ding Y, Li M, Wang PG. 2010. In vitro bacterial polysaccharide biosynthesis: defining the functions of Wzy and Wzz. Nat. Chem. Biol. 6:418-423.

42. Islam ST, Gold AC, Taylor VL, Anderson EM, Ford RC, Lam JS. 2011. Dual conserved periplasmic loops possess essential charge characteristics that support a catchand-release mechanism of O-antigen polymerization by Wzy in Pseudomonas aeruginosa PAO1. J. Biol. Chem. 286:20600-20605.

43. Islam ST, Huszczynski SM, Nugent T, Gold AC, Lam JS. 2013. Conserved-residue mutations in Wzy affect O-antigen polymerization and Wzz-mediated chain-length regulation in Pseudomonas aeruginosa PAO1. Sci. Rep. 3:3441.

44. Cuthbertson L, Mainprize IL, Naismith JH, Whitfield C. 2009. Pivotal roles of the outer membrane polysaccharide export and polysaccharide copolymerase protein families in export of extracellular polysaccharides in Gram-negative bacteria. Microbiol. Mol. Biol. Rev. 73:155-177.

45. Kato T, Shirakawa Y, Takegawa K, Kimura Y. 2015. Functional analysis of conserved motifs in a bacterial tyrosine kinase, BtkB, from Myxococcus xanthus. J. Biochem. 158:385-392.

46. Kimura Y, Kato T, Mori Y. 2012. Function analysis of a bacterial tyrosine kinase, BtkB, in Myxococcus xanthus. FEMS Microbiol. Lett. 336:45-51.

47. Kimura Y, Yamashita S, Mori Y, Kitajima Y, Takegawa K. 2011. A Myxococcus xanthus bacterial tyrosine kinase, BtkA, is required for the formation of mature spores. $\mathrm{J}$. Bacteriol. 193:5853-5857.

48. Standish AJ, Morona R. 2014. The role of bacterial protein tyrosine phosphatases in the regulation of the biosynthesis of secreted polysaccharides. Antioxid. Redox Signal. 20:2274-2289.

49. Mori Y, Maeda M, Takegawa K, Kimura Y. 2012. PhpA, a tyrosine phosphatase of Myxococcus xanthus, is involved in the production of exopolysaccharide. Microbiology 158:2546-2555. 
50. Nickerson NN, Mainprize IL, Hampton L, Jones ML, Naismith JH, Whitfield C. 2014. Trapped translocation intermediates establish the route for export of capsular polysaccharides across Escherichia coli outer membranes. Proc. Natl. Acad. Sci. USA 111:8203-8208.

51. Dong C, Beis K, Nesper J, Brunkan-LaMontagne AL, Clarke BR, Whitfield C, Naismith JH. 2006. Wza the translocon for $E$. coli capsular polysaccharides defines a new class of membrane protein. Nature 444:226.

52. Yang Z, Geng Y, Xu D, Kaplan HB, Shi W. 1998. A new set of chemotaxis homologues is essential for Myxococcus xanthus social motility. Mol. Microbiol. 30:1123-1130.

53. Yang Z, Li Z. 2005. Demonstration of interactions among Myxococcus xanthus Dif chemotaxis-like proteins by the yeast two-hybrid system. Arch. Microbiol. 183:243-252.

54. Lancero HL, Castaneda S, Caberoy NB, Ma X, Garza AG, Shi W. 2005. Analysing protein-protein interactions of the Myxococcus xanthus Dif signalling pathway using the yeast two-hybrid system. Microbiology 151:1535-1541.

55. Yang Z, Ma X, Tong L, Kaplan HB, Shimkets LJ, Shi W. 2000. Myxococcus xanthus dif genes are required for biogenesis of cell surface fibrils essential for social gliding motility. J. Bacteriol. 182:5793-5798.

56. Bellenger K, Ma X, Shi W, Yang Z. 2002. A CheW homologue is required for Myxococcus xanthus fruiting body development, social gliding motility, and fibril biogenesis. J. Bacteriol. 184:5654-5660.

57. Black WP, Wang L, Davis MY, Yang Z. 2015. The orphan response regulator EpsW is a substrate of the DifE kinase and it regulates exopolysaccharide in Myxococcus xanthus. Sci. Rep. 5:17831.

58. Black WP, Yang Z. 2004. Myxococcus xanthus chemotaxis homologs DifD and DifG negatively regulate fibril polysaccharide production. J. Bacteriol. 186:1001-1008.

59. Wu SS, Wu J, Kaiser D. 1997. The Myxococcus xanthus pilT locus is required for social gliding motility although pili are still produced. Mol. Microbiol. 23:109-121.

60. Shimkets LJ. 1986. Correlation of energy-dependent cell cohesion with social motility in Myxococcus xanthus. J. Bacteriol. 166:837-841.

61. Weimer RM, Creighton C, Stassinopoulos A, Youderian P, Hartzell PL. 1998. A chaperone in the HSP70 family controls production of extracellular fibrils in Myxococcus xanthus. J. Bacteriol. 180:5357-5368.

62. Yang Z, Geng Y, Shi W. 1998. A DnaK homolog in Myxococcus xanthus is involved in social motility and fruiting body formation. J. Bacteriol. 180:218-224. 
63. Arnold JW, Shimkets LJ. 1988. Cell surface properties correlated with cohesion in Myxococcus xanthus. J. Bacteriol. 170:5771-5777.

64. Overgaard M, Wegener-Feldbrügge S, Søgaard-Andersen L. 2006. The orphan response regulator DigR is required for synthesis of extracellular matrix fibrils in Myxococcus xanthus. J. Bacteriol. 188:4384-4394.

65. Lu A, Cho K, Black WP, Duan X-y, Lux R, Yang Z, Kaplan HB, Zusman DR, Shi W. 2005. Exopolysaccharide biosynthesis genes required for social motility in Myxococcus xanthus. Mol. Microbiol. 55:206-220.

66. Ward MJ, Lew H, Zusman DR. 2000. Social motility in Myxococcus xanthus requires FrzS, a protein with an extensive coiled-coil domain. Mol. Microbiol. 37:1357-1371.

67. Rosenbluh A, Eisenbach M. 1992. Effect of mechanical removal of pili on gliding motility of Myxococcus xanthus. J. Bacteriol. 174:5406-5413.

68. Shi W, Yang Z, Sun H, Lancero H, Tong L. 2000. Phenotypic analyses of frz and dif double mutants of Myxococcus xanthus. FEMS Microbiol. Lett. 192:211-215.

69. Zhou T, Nan B. 2017. Exopolysaccharides promote Myxococcus xanthus social motility by inhibiting cellular reversals. Mol. Microbiol. 103:729-743.

70. Black WP, Xu Q, Yang Z. 2006. Type IV pili function upstream of the Dif chemotaxis pathway in Myxococcus xanthus EPS regulation. Mol. Microbiol. 61:447-456.

71. Rosenberg M, Gutnick D, Rosenberg E. 1980. Adherence of bacteria to hydrocarbons: a simple method for measuring cell-surface hydrophobicity. FEMS Microbiol. Lett. 9:29-33.

72. Kupfer D, Zusman DR. 1984. Changes in cell surface hydrophobicity of Myxococcus xanthus are correlated with sporulation-related events in the developmental program. J. Bacteriol. 159:776-779.

73. Kaczorek E, Pacholak A, Zdarta A, Smulek W. 2018. The impact of biosurfactants on microbial cell properties leading to hydrocarbon bioavailability increase. Colloids Interfaces 2:35.

74. Behmlander RM, Dworkin M. 1991. Extracellular fibrils and contact-mediated cell interactions in Myxococcus xanthus. J. Bacteriol. 173:7810-7820.

75. Kim S-H, Ramaswamy S, Downard J. 1999. Regulated exopolysaccharide production in Myxococcus xanthus. J. Bacteriol. 181:1496-1507.

76. Dworkin M. 1999. Fibrils as extracellular appendages of bacteria: their role in contactmediated cell-cell interactions in Myxococcus xanthus. BioEssays 21:590-595.

77. Behmlander RM, Dworkin M. 1994. Biochemical and structural analyses of the extracellular matrix fibrils of Myxococcus xanthus. J. Bacteriol. 176:6295-6303. 
78. Dana JR, Shimkets LJ. 1993. Regulation of cohesion-dependent cell interactions in Myxococcus xanthus. J. Bacteriol. 175:3636-3647.

79. Merroun ML, Ben Chekroun K, Arias JM, González-Muñoz MT. 2003. Lanthanum fixation by Myxococcus xanthus: cellular location and extracellular polysaccharide observation. Chemosphere 52:113-120.

80. Mauriello EMF, Mignot T, Yang Z, Zusman DR. 2010. Gliding motility revisited: how do the myxobacteria move without flagella? Microbiol. Mol. Biol. Rev. 74:229-249.

81. Gloag ES, Turnbull L, Javed MA, Wang H, Gee ML, Wade SA, Whitchurch CB. 2016. Stigmergy co-ordinates multicellular collective behaviours during Myxococcus xanthus surface migration. Sci. Rep. 6:26005.

82. Gloag ES, Turnbull L, Whitchurch CB. 2015. Bacterial stigmergy: an organising principle of multicellular collective behaviours of bacteria. Scientifica (Cairo) 2015:387342.

83. Kearns DB, Campbell BD, Shimkets LJ. 2000. Myxococcus xanthus fibril appendages are essential for excitation by a phospholipid attractant. Proc. Natl. Acad. Sci. U. S. A. 97:11505-11510.

84. Fontes M, Kaiser D. 1999. Myxococcus cells respond to elastic forces in their substrate. Proc. Natl. Acad. Sci. USA 96:8052-8057.

85. Lemon DJ, Yang X, Srivastava P, Luk Y-Y, Garza AG. 2017. Polymertropism of rodshaped bacteria: movement along aligned polysaccharide fibers. Sci. Rep. 7:7643.

86. Lemon DJ, Schutzman DA, Garza AG. 2018. Bacterial surface spreading is more efficient on nematically aligned polysaccharide substrates. J. Bacteriol. 200:e00610-00617.

87. Luft JH. 1971. Ruthenium red and violet. I. Chemistry, purification, methods of use for electron microscopy and mechanism of action. Anat. Rec. 171:347-368.

88. Burchard RP. 1975. Myxospore induction in a nondispersed growing mutant of Myxococcus xanthus. J. Bacteriol. 122:302-306.

89. MacRae TH, McCurdy HD. 1976. Evidence for motility-related fimbriae in the gliding microorganism Myxococcus xanthus. Can. J. Microbiol. 22:1589-1593.

90. Sun H, Zusman DR, Shi W. 2000. Type IV pilus of Myxococcus xanthus is a motility apparatus controlled by the frz chemosensory system. Curr. Biol. 10:1143-1146.

91. Hu W, Hossain M, Lux R, Wang J, Yang Z, Li Y, Shi W. 2011. Exopolysaccharideindependent social motility of Myxococcus xanthus. PLoS ONE 6:e16102. 
92. Guzzo M, Agrebi R, Espinosa L, Baronian G, Molle V, Mauriello EMF, BrochierArmanet C, Mignot T. 2015. Evolution and design governing signal precision and amplification in a bacterial chemosensory pathway. PLoS Genet. 11:e1005460.

93. Tréguier J, Bugnicourt L, Gay G, Diallo M, Islam ST, Toro A, David L, Théodoly O, Sudre G, Mignot T. 2019. Chitosan films for microfluidic studies of single bacteria and perspectives for antibiotic susceptibility testing. mBio 10:e01375-01319.

94. Mercier R, Mignot T. 2016. Regulations governing the multicellular lifestyle of Myxococcus xanthus. Curr. Opin. Microbiol. 34:104-110.

95. Fassel TA, Edmiston Jr. CE. 1999. Ruthenium red and the bacterial glycocalyx. Biotech. Histochem. 74:194-212.

96. Hanke DE, Northcote DH. 1975. Molecular visualization of pectin and DNA by ruthenium red. Biopolymers 14:1-17.

97. Charuk JHM, Pirraglia CA, Reithmeier RAF. 1990. Interaction of ruthenium red with $\mathrm{Ca}^{2+}$-binding proteins. Anal. Biochem. 188:123-131.

98. Voelker D, Smejtek P. 1996. Adsorption of ruthenium red to phospholipid membranes. Biophys. J. 70:818-830.

99. Sutherland IW, Thomson S. 1975. Comparison of polysaccharides produced by Myxococcus strains. J. Gen. Microbiol. 89:124-132.

100. Gibiansky ML, Hu W, Dahmen KA, Shi W, Wong GCL. 2013. Earthquake-like dynamics in Myxococcus xanthus social motility. Proc. Natl. Acad. Sci. USA 110:23302335 .

101. Hu W, Li L, Sharma S, Wang J, McHardy I, Lux R, Yang Z, He X, Gimzewski JK, Li Y, Shi W. 2012. DNA builds and strengthens the extracellular matrix in Myxococcus xanthus biofilms by interacting with exopolysaccharides. PLOS ONE 7:e51905.

102. MacLean L, Perry MB, Nossova L, Kaplan H, Vinogradov E. 2007. The structure of the carbohydrate backbone of the LPS from Myxococcus xanthus strain DK1622. Carbohydr. Res. 342:2474-2480.

103. Curtis PD, Atwood J, Orlando R, Shimkets LJ. 2007. Proteins associated with the Myxococcus xanthus extracellular matrix. J. Bacteriol. 189:7634-7642.

104. Ducret A, Quardokus EM, Brun YV. 2016. MicrobeJ, a tool for high throughput bacterial cell detection and quantitative analysis. Nat. Microbiol. 1:16077. 


\section{FIGURE LEGENDS}

825 Figure 1. (A) Motility and developmental phenotypes for various mutants with altered levels of

826

827

828

829

830

831

832

833

834

835

836

837

838

839

840

841

842

843

844

845

846

secreted polysaccharides. Top panels (upper): gliding motility flares on CYE $1.5 \%$ agar after 30

$\mathrm{h}$ (scale bar: $50 \mu \mathrm{m})$. Top panels (lower): magnified view of white hatched box in corresponding

upper panel showing furrows in the agar substratum containing transiting cell groups (scale bar:

$10 \mu \mathrm{m})$. Arrowheads $(\triangleright)$ indicate furrows in the agar left by previously-transited cells and/or

cell groups, revealed by extreme oblique illumination of agar surface. Middle panels: T4P-

dependent swarm spreading on CYE $0.5 \%$ agar after $72 \mathrm{~h}$ (scale bar: $2 \mathrm{~mm}$ ). Bottom panels:

fruiting body formation on CF $1.5 \%$ agar after $75 \mathrm{~h}$ (scale bar: $1 \mathrm{~mm}$ ). (B) Bar graphs of

diameters of swarms grown on CYE $0.5 \%$ agar for T4P-dependent motility at $72 \mathrm{~h}$. For each

strain, the mean value of 3 biological replicates (+/-SEM) is plotted. Asterisks (*) denote

datasets displaying statistically significant differences $(p<0.0001)$ relative to both WT and

$\Delta d i f G$ strains, as determined via unpaired two-tailed Student's t-test analyses.

Figure 2. Auto-aggregation profiles of WT, $\operatorname{EPS}^{-}(\Delta w z a X), \mathrm{BPS}^{-}(\Delta w z a B)$, and $\Omega$ pilA strains resuspended in (A) CYE rich medium (mean values of 6, 6, 6, and 5 biological replicates [+/SEM], respectively) and (B) TPM minimal buffer (mean values of 3 biological replicates [+/-

SEM]). (C) Representative transmission electron micrographs of WT, BPS ${ }^{-}(\Delta w z a B)$, and EPS

$(\Delta w z a X)$ cells on copper grids, taken at $10000 \times$ magnification (scale bar: $500 \mathrm{~nm})$. Arrowheads

$(\triangleright)$ denote thin (likely single) T4P filaments. Arrows $(\Rightarrow)$ denote thick (likely bundled) T4P

filaments. Asterisks (*) denote cell poles. (D) Boxplots of Trypan Blue dye retention to indicate the levels of EPS production in various strains relative to WT. The lower and upper boundaries of the boxes correspond to the $25^{\text {th }}$ and $75^{\text {th }}$ percentiles, respectively. The median (line through 
847 centre of boxplot) and mean (+) of each dataset are indicated. Lower and upper whiskers

848 represent the $10^{\text {th }}$ and $90^{\text {th }}$ percentiles, respectively; data points above and below the whiskers are

849 drawn as individual points. Asterisks denote datasets displaying statistically significant

850 differences in distributions $(p<0.05)$ shifted higher $(* *)$ or lower $(*)$ than WT, as determined via

851 Wilcoxon signed-rank test performed relative to "100". Data for $\Delta$ difE and $\Delta$ difG was

852 heretofore unreported and acquired at the same time as the published values for other strains

853 (32), reproduced with permission. (E) Microbial adhesion to hydrocarbons (MATH) test of WT

854 and $\mathrm{BPS}^{-}(\triangle w z a B)$ strain binding to hexadecane; values are the mean of 3 biological replicates

855 (+/- SEM). Mix 1, initial pellet resuspension in CYE; Mix 2, supplemental control mixing; Mix

8563 , mixing upon addition of hexadecane $(t=0)$. Asterisk $(*)$ denotes dataset displaying

857 statistically significant difference in time point mean value $(p=0.0176)$ compared to WT, as

858 determined via unpaired Student's t test. (F) Scanning electron micrographs of WT, EPS ${ }^{-}$

$859(\Delta w z a X)$, and $\mathrm{BPS}^{-}(\Delta w z a B)$ cells, taken at $20000 \times$ magnification (scale bar: $\left.1.0 \mu \mathrm{m}\right)$. Arrows

860 denote EPS fibrils connecting cells. Arrowheads denote potential surface-associated fibril

861 material not engaged in inter-cell connections.

862

863 Figure 3. (A) Violin plots of single-cell gliding event speeds for WT, $\mathrm{EPS}^{-}(\Delta w z a X)$, and BPS

$864(\triangle w z a B)$ cells on $1.5 \%$ agar pads $(\mathrm{n}=2298$ events across 4 biological replicates $)$. A gliding

865 event was defined as an instance of continuous translocation in a given direction. Cessation of

866 motion by a given cell, followed by either a resumption of gliding in the same direction or a

867 reversal of gliding direction, was considered the beginning of a new gliding event. The lower

868 and upper boundaries of the plots correspond to the minimum and maximum values of the

869 dataset, with the $25^{\text {th }}$ and $75^{\text {th }}$ percentiles displayed (thick hatched black lines). The median 
870 (solid black line) and mean $(+)$ of each dataset are indicated. Asterisks denote datasets displaying

871 statistically significant differences in distributions $(p<0.0001)$ between $(*) \mathrm{WT}$ and $\mathrm{EPS}^{-} / \mathrm{BPS}^{-}$

872 cells, as well as between (**) $\mathrm{EPS}^{-}$and $\mathrm{BPS}^{-}$cells, as determined via unpaired two-tailed Mann-

873 Whitney test. (B) Boxplots of reversals per minute for tracked WT, EPS ${ }^{-}$, and $\mathrm{BPS}^{-}$single cells

874 on $1.5 \%$ agar pads ( $\mathrm{n}=1135$ cells across 4 biological replicates). The lower and upper

875 boundaries of the boxes correspond to the $25^{\text {th }}$ and $75^{\text {th }}$ percentiles, respectively. The median

876 (line through centre of boxplot) and mean $(+)$ of each dataset are indicated. Lower and upper

877 whiskers represent the $10^{\text {th }}$ and $90^{\text {th }}$ percentiles, respectively; data points above and below the

878 whiskers are drawn as individual points. Asterisks denote datasets displaying statistically

879 significant differences in distributions between (*) WT and EPS ${ }^{-}$cells $(p=0.0424),(* *)$ WT

880 and $\mathrm{BPS}^{-}$cells $(\mathrm{p}<0.0001)$, and $(* * *) \mathrm{EPS}^{-}$and $\mathrm{BPS}^{-}$cells $(\mathrm{p}<0.0001)$, as determined via

881 unpaired two-tailed Mann-Whitney tests. (C) Violin plots of polymertropism responses for WT,

$882 \operatorname{EPS}^{-}(\Delta w z a X)$, and $\mathrm{BPS}^{-}(\Delta w z a B)$ polysaccharide secretion mutant strains. The lower and upper

883 boundaries of the plots correspond to the minimum and maximum values of the dataset, with the

$88425^{\text {th }}$ and $75^{\text {th }}$ percentiles displayed (thick hatched black lines). The median (solid black line) and

885 mean (+) of each dataset are indicated. Asterisks denote datasets displaying statistically

886 significant differences in distributions between $(*)$ WT and BPS ${ }^{-}$swarms $(p=0.0006)$ and $(* *)$

887 EPS $^{-}$and BPS ${ }^{-}$swarms $(\mathrm{p}=0.0232)$, whereas distributions between WT and $\mathrm{EPS}^{-}$swarms were

888 not significantly different $(\mathrm{p}=0.0845)$, as determined via unpaired two-tailed Mann-Whitney

889 test. The number of biological replicates $(n)$ used to analyze each strain as follows: WT (11),

$890 \Delta w z a X(10), \Delta w z a B(10)$.

891 
892 Figure 4. TEM analysis of Ruthenium Red-stained transverse sections cut from WT, MASC

$893(\Delta w z a S), \mathrm{BPS}^{-}(\Delta w z a B)$, and $\mathrm{EPS}^{-}(\Delta w z a X)$ swarms. Left-side panels, inset: relative position of

894 sample sectioning prior to TEM. Left-side panels: wide-angle views at 4000× magnification of

895 internal swarm architecture. For reference, the agar substratum and the apical face of the swarm

896 were located at the bottom and top (respectively) of each image. Scale bar: $1 \mu \mathrm{m}$. Right-side

897 panels: magnified views $(20000 \times)$ of the corresponding zone within white hatched boxes in the

898 left-side panels. Scale bar: $100 \mathrm{~nm}$. Arrows $(\rightarrow)$ denote wispy putative polysaccharide-like

899 material. Filled arrowheads $(\triangleright)$ denote OMVs. Chevrons (>) denote OMV chains. 


\section{AUTHOR CONTRIBUTIONS}

901 FS and STI conceived of and planned the study.

902 FS and NYJ performed stereoscopic phenotypic analyses and measured colony surface areas.

903 AN, FS, and NYJ prepared samples for electron microscopy

904 AN, FS, and NYJ performed transmission electron microscopy, while the former two performed

905 scanning electron microscopy.

906 FS performed dye-binding assays.

907 STI performed auto-aggregation analyses.

908 FS tested strain hydrophobicity.

909 NYJ quantified cell motility and cell reversals.

910 DJL tested polymertropism responses, with analysis by STI and DJL.

911 FS, NYJ, and STI wrote the manuscript.

912 FS, NYJ, and STI generated figures.

913 STI, AGG, and FJV contributed personnel and funding support. 


\section{FIGURE 1}

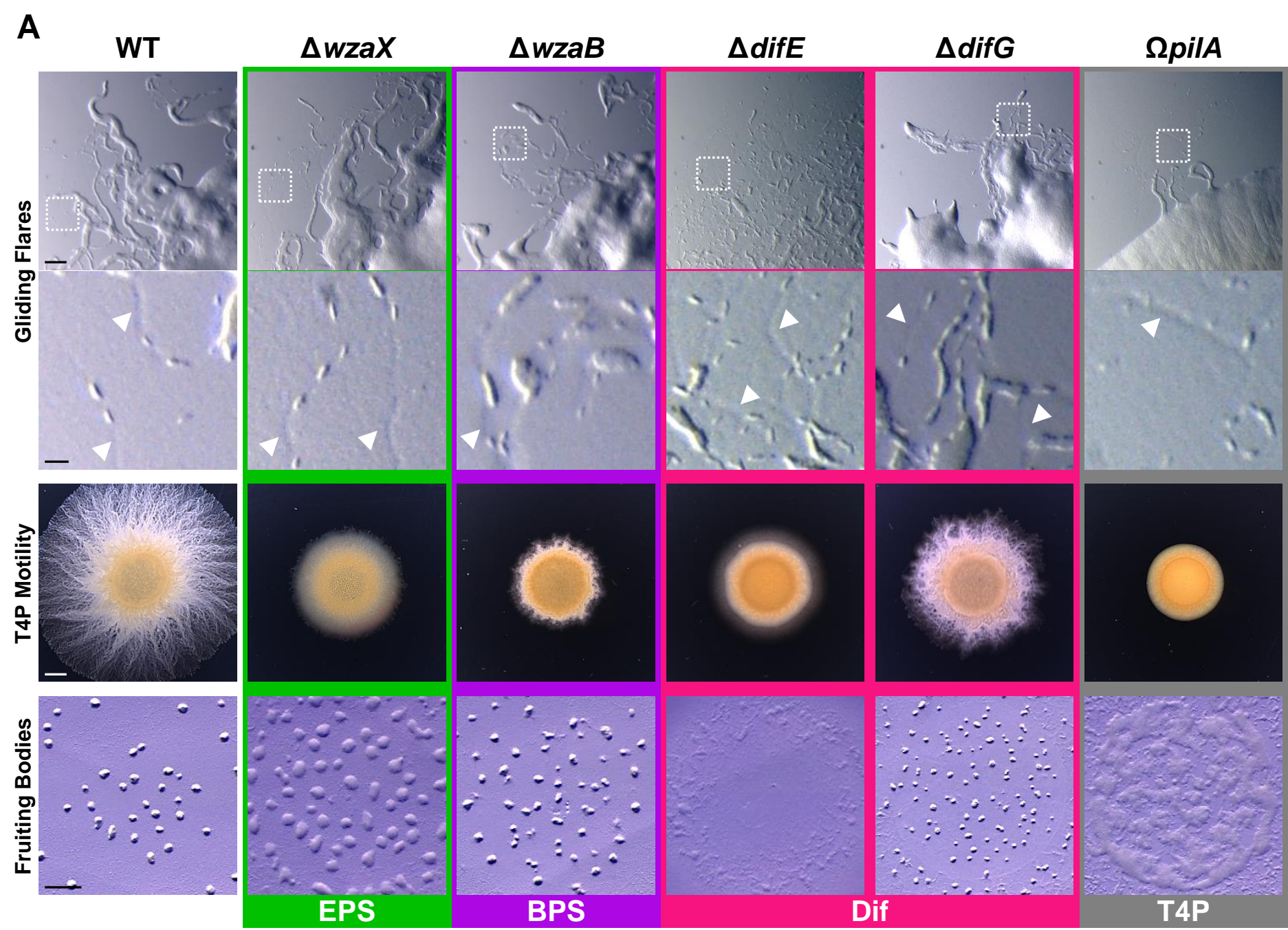

B

T4P-Dependent Swarm Spreading

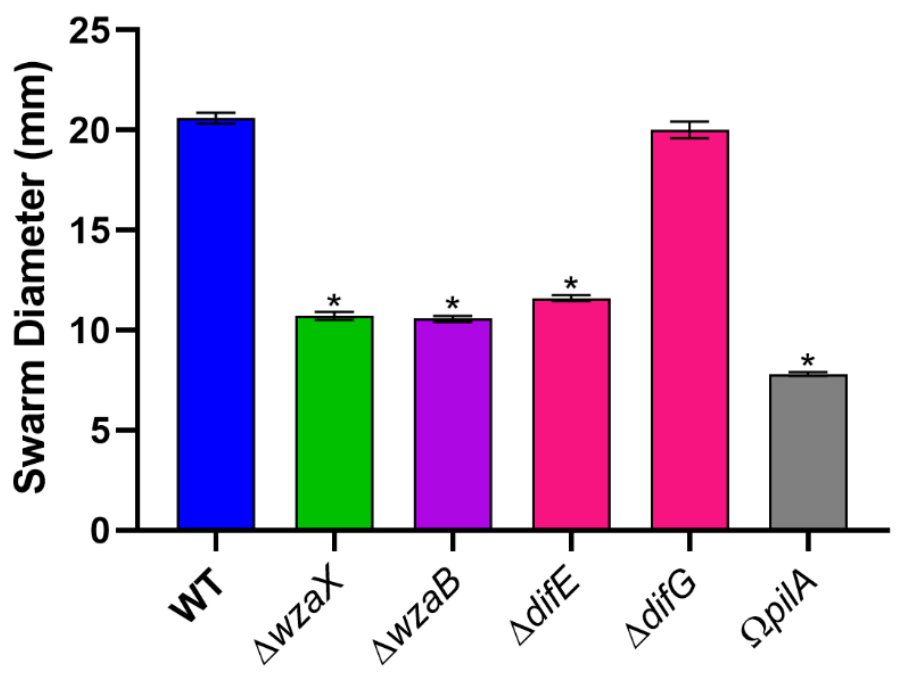

Strain 
A

Single-Cell

Gliding Speed

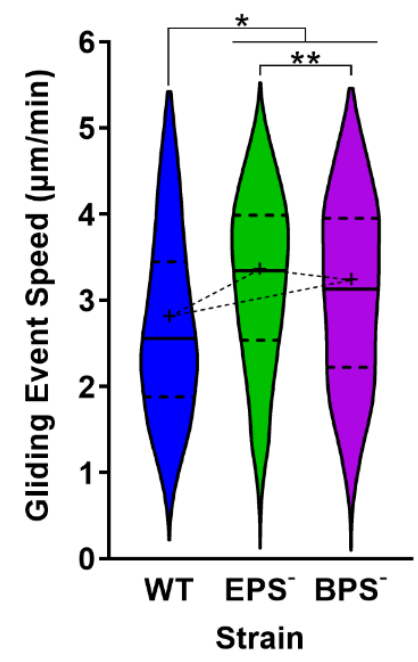

B

Gliding Direction Reversal Frequency

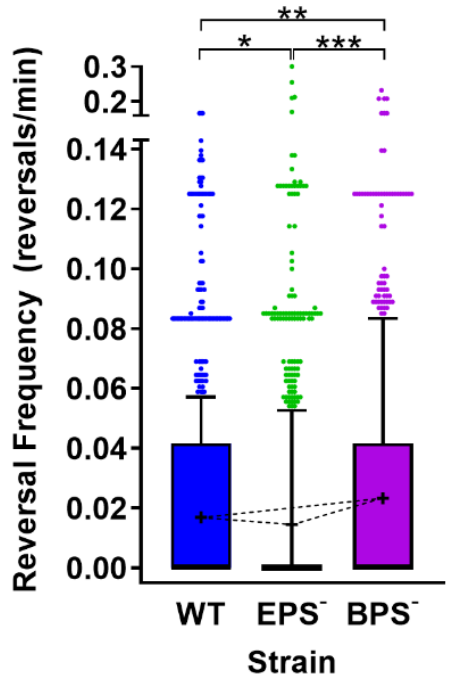

C

Polymertropism Response

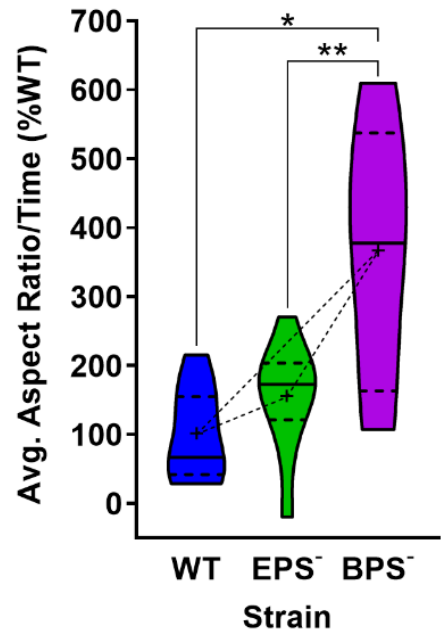




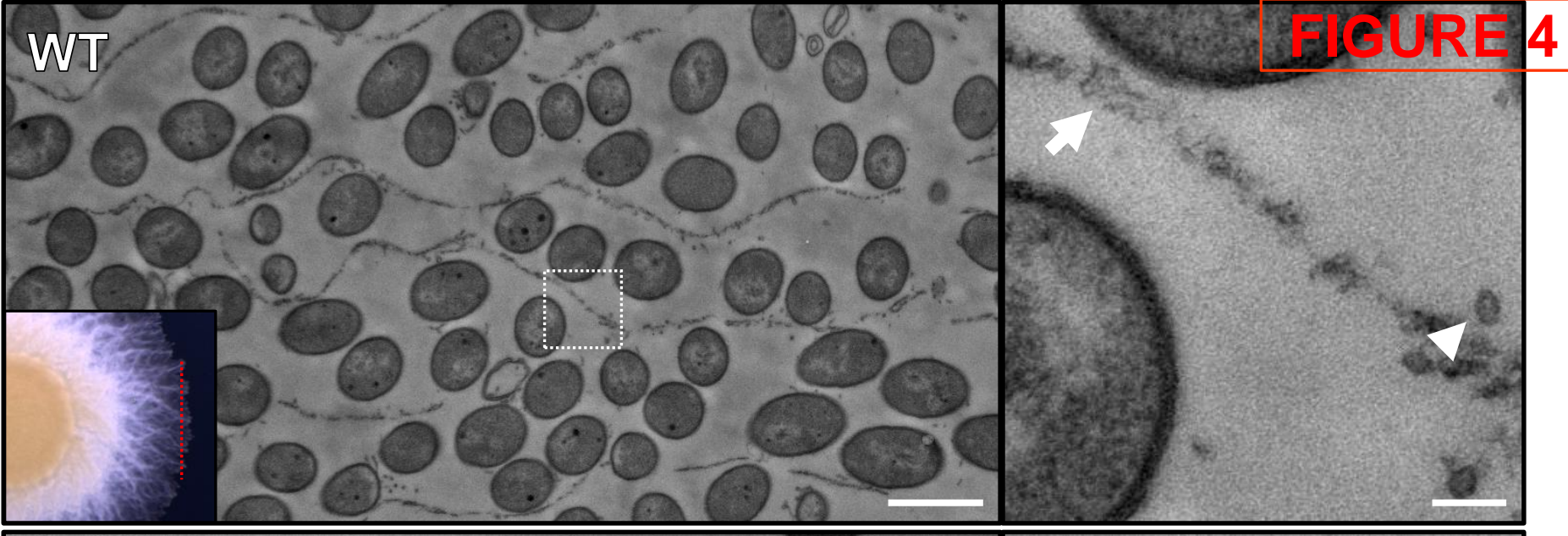

MASC-

320

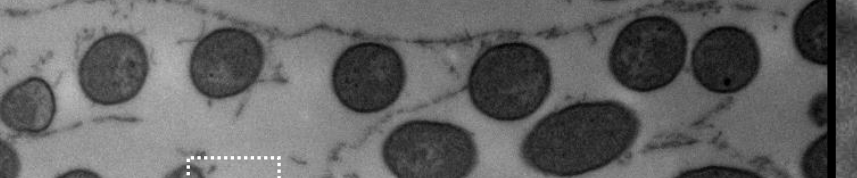

00000

90
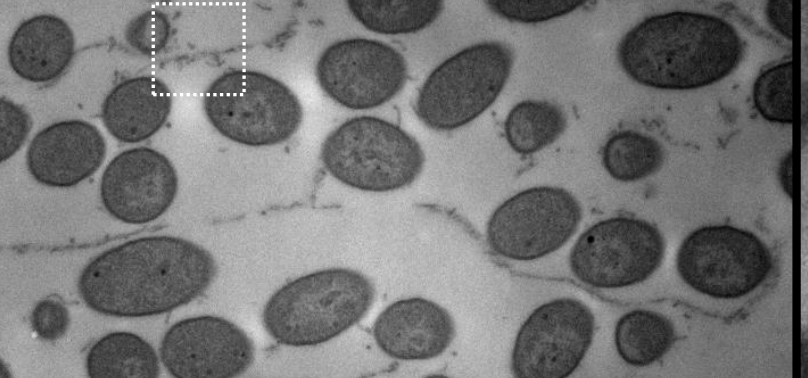

$\pi$

1

BPS $90000000 \%$ 3200000000 008080000

2008008\% $00 \%$

8

00000 $0090.00 \%$ $380 \% 280^{\circ} \circ$

\section{EPS-}

(2) 
$\underline{\text { Strain }}$ Strain

Code

TM108 Myxococcus xanthus DZ2

TM469 $\Delta w z a X$

TM484 $\Delta w z a S$

TM529 $\Delta w z a B$

EM450 $\triangle$ difE

EM451 $\Delta$ difG

TM293 SpilA
Genotype/

Description

Wild type

$\Delta m x a n \_7417 / e p s Y$

$\Delta m x a n \_3225 / e x o A / f d g A$

$\Delta m x a n \_1915$

$\Delta m x a n \_6692$

$\Delta m x a n \_6691$

Smxan_5783 $\left(\right.$ Tet $^{\mathrm{R}}$

cassette insertion)
Laboratory collection

Source or

Reference

Laboratory collection

[1]

[1]

[1]

[2]

Laboratory collection

[1] Ducret A, Valignat M-P, Mouhamar F, Mignot T, Theodoly O. Wet-surface-enhanced ellipsometric contrast microscopy identifies slime as a major adhesion factor during bacterial surface motility. Proc. Natl. Acad. Sci. U. S. A. 2012. 109(25):10036-10041.

[2] Moine A, Agrebi R, Espinosa L, Kirby JR, Zusman DR, Mignot T, Mauriello EMF. Functional organization of a multimodular bacterial chemosensory apparatus. PLOS Genet. 2014. 10(3):e1004164 